\title{
Low Cost Automation System for Smart Houses based on PIC Microcontrollers
}

\author{
Fathia Chekired \\ Unité de Développement des \\ Equipements Solaires \\ UDES / EPST CDER \\ Tipaza, Algeria \\ chekiredfathya@yahoo.fr
}

\author{
Abdellah Rahmani \\ Ecole Nationale Polytechnique \\ Algiers, Algeria \\ abdellah.rahmani@g.enp.edu.dz
}

\author{
Smail Houtti \\ Ecole Nationale Polytechnique \\ Algiers, Algeria \\ smail.houti@g.enp.edu.dz
}

Amar Tilmatine

IEEE Senior Member

Université de Sidi Bel Abbès

APELEC Laboratory

Sidi Bel Abbès, Algeria

atilmatine@gmail.com

\author{
Constantinos A. Bouroussis \\ Lighting Laboratory, National \\ Technical University of Athens, \\ Athens, Greece, \\ costisb@mail.ntua.gr
}

\begin{abstract}
The high electricity bills of houses have triggered a significant research for solutions to mitigate this issue. The house automation systems offer everything necessary to put an end to these inconveniences as, most often, they incorporate a number of smart devices (microcontrollers and sensors). The presented work outlines the development of a microcontroller-based automation system of a solar smart house using automatic lighting and thermal comfort sensors (temperature, humidity) and safety functions (gas leakage, smoke detection). This system is based on PIC microcontrollers and is applied through the implementation of a complete algorithm. The program is written on Micro $\mathrm{C}$, and in order to realize the control circuit and the simulation, the testing software made use of Proteus software which is freely available from the Internet. The control of temperature and air pollution was implemented using the PIC16F877A, while the light control was applied with the PIC18F4550. The hardware prototype was also provided to experiment on the designed control strategy. The results of this work allowed some conclusions to be reached and confirmed the benefits of this kind of automation systems.
\end{abstract}

Keywords-Smart house, Automatic control, Smart lighting, Microcontrollers, Home sensors, Low cost.

\section{INTRODUCTION}

In Algeria, the residential sector appears as one of the biggest energy consumers as it represents about $43 \%$ of the national lighting consumption [1] and contributes also to increasing of the global warming. In 2015, the Algerian government adopted an update to its Renewable Energy and Energy Efficiency Development Plan until 2030 [2]. The question of Energy production and environmental carbon impact have been considered very seriously in the economic development of Algeria [3, 4]. With the energy production, the energy saving constitutes the second part in the field of energies management. Smart-Cities or Smart Houses aim to intelligent energy management which is the only way to

Funded by French Ministry of Europe and Foreign Affairs and Algerian Ministry of Higher Education and Scientific Research as a part of Program Hubert Curien "Maghreb" MELINA granted to L.C. optimize energy usage. In the current energy context, the protection of the environment goes through the energy transition, which recommends the progressive use of Renewable Energies instead of the fossil resources. On the other hand, beside the improvement of house's thermal insulation and efficient consumer appliances, reducing the energy demand also means the introduction of home automation. This is mainly due to the appliances and the various electronic devices used at daily homes $[5,6]$.

Through literature review, different lighting control techniques and technologies were studied [7]. Integrated lighting controls can significantly improve building performance, energy efficiency, and enhance occupant comfort and satisfaction with the built environment [8 - 10]. While several research studies concluded that simple lighting controls such, as occupancy sensors, are effective in reducing the amount of electric energy for lighting in buildings, advanced lighting control strategies have the potential to achieve even greater energy savings and offer many advantages over simple control [11, 12]. According to [13], lighting control system or device is considered as an apparatus that, receives information, decides what to do with that information, and changes the operation of the lighting system. The lighting control system is not a security device and should not be considered as that such. It provides convenient access and intelligent features that makes it distinct from all other lit rooms which bring it so close to a security device.

Although that Domestic Energy management is considered as a developed subject however it is generally based on expensive compounds like CCD camera. Therefore, the proposed solutions are difficult to be applied in developing countries $[14,15]$. The objective of this work is to develop a low-cost system focused on automation and indoor lighting that also includes air quality, security and comfort criteria.

\section{CASE STUdy}


The dwelling object of the study is a $57 \mathrm{~m}^{2}$ house installed in UDES (Unité de Développement des Équipements Solaire) at Bou-Ismaïl (Latitude: $36^{\circ} 38^{\prime} 33^{\prime}$, North; Longitude: $36^{\circ} 38^{\prime} 33^{\prime \prime}$ 'North) situated in a coastal region at $40 \mathrm{~km}$ far from Algiers. This house is devoted to be mainly fed by photovoltaic electricity. The house is equipped with a photovoltaic system which consists of a $3.2 \mathrm{kWp}$ multi-crystalline silicon $(\mathrm{m}-\mathrm{Si}) \mathrm{PV}$ generator, on the roof and facing the south with a $20^{\circ}$ of tilt angle to the horizontal, a $12 \mathrm{kWh}$ lead-acid battery storage and a $4 \mathrm{kWp}$ gridconnected inverter $[5,16]$. The purpose of this work is to automate the artificial lighting and secure the house by integrating various sensors in order to command and control them via the microcontrollers. First, an electronic circuit was developed and tested in laboratory in order to develop a control algorithm and test its effectiveness. Secondly, the developed device was applied on the house under consideration.

\section{GENERAL OVERVIEW OF THE SYSTEM}

Home automation dealing with lighting and comfort (temperature, humidity, security) is presented in Fig. 1. The system is composed of three stages:

- Heating control unit: The first stage is the Heating Control Unit which allows the heating or air conditioning of the house based on the indoor and outdoor temperature

- Ventilation control unit: The second stage concerns the quality of ambient air in the house which is evaluated by two parameters, which are the humidity and the air pollution, to allow or not the ventilation of the home

- Lighting control unit: The last stage is for the lighting control, which, depending on the outdoor and indoor light conditions and the presence or the absence of the inhabitants, permits or not the lighting in the house.

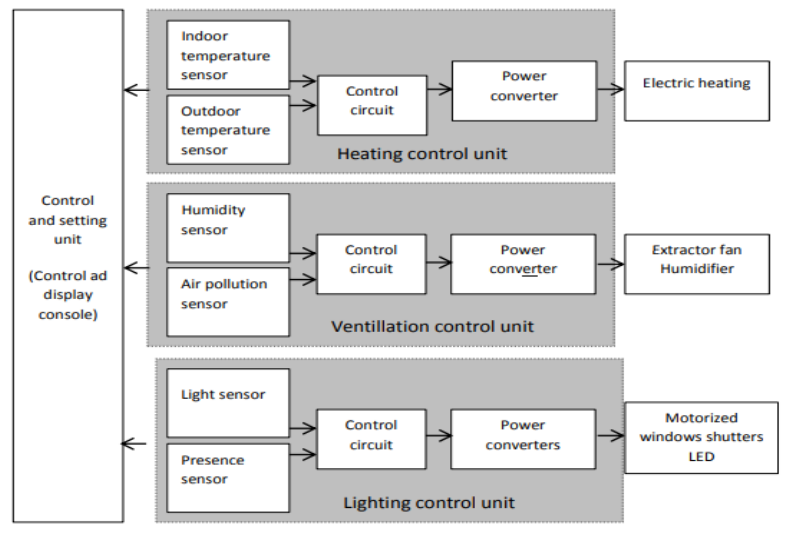

Fig. 1. Home automation system composition

\section{HOME AUTOMATION SYSTEM DESIGN}

The operating principles used for the control system of lighting, air quality, heating and air conditioning of the house have been implemented on the microcontrollers. The PIC16F877A was used for the Lighting and the PIC18F4550 for the heating, air conditioning and the ventilation of the home. A first straightforward solution is to exploit the daylight to a maximum: turn off the lights and open the window shutters as long as is the sun offers adequate illumination levels. Therefore, an automatic opening/closing system of the shutters could be implemented according to the rate of external light. However, in cloudy weather (in winter), since outside light is dim interior lighting becomes necessary. The solution proposed in this case, is to illuminate gradually in order to compensate the lack of brightness. Thus, the lamps will be set on at a given percentage of their maximal power in respect of the external light by using the PWM technique (pulse width modulation). During the night, the power of the lamps will be set at a predefined level to achieve the needed illumination levels. It is also possible to optimize energy simply by turning off the lamps when leaving a room, because people generally forget the lights turned on. To face this, the powering of the lamps will be conditioned by the presence of individuals in the room by utilizing presence sensors.

Fig. 2 presents home automation conception including: automatic lighting, thermal comfort (temperature, humidity) and safety functions (gas leakage, smoke detection). Fig. 3 presents the proposed automatic lighting algorithm.

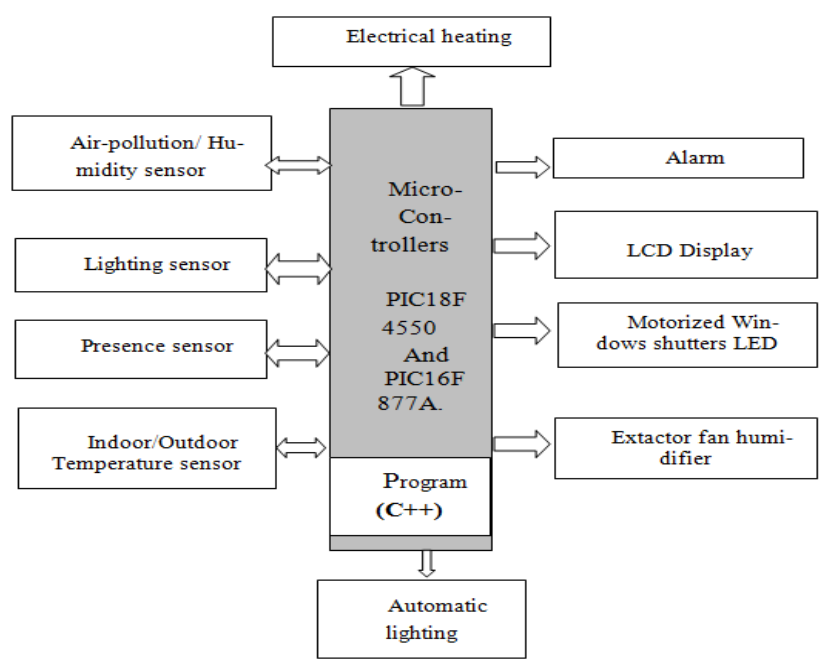

Fig. 2. Home automation conception

Below are the control factors that were considered in the present study.

a. Windows shutters: If the external light ratio is greater than or equal to a predefined reference value (depending on sunrise time), then the motor is actuated in the flap opening direction. Otherwise, if the brightness level is too low (night), then the motor is actuated in the closing direction of the shutters.

b. Lighting: If the external brightness level is sufficient, then all the LED (Light Emitting Diode) lamps are switched off while the shutters are already opened. Otherwise, $I F$ it is insufficient but not too weak $A N D$ there is at least one person in the room, THEN the LEDs are half powered. Moreover, IF the brightness level is too low (night) $A N D$ there is at least one person in the room, THEN the LEDs become illuminated at the predefined max level. 
c. Temperature: The temperature effect should be considered if the difference between the indoor and the reference temperatures is greater than or equal to the limit threshold. In this case, $I F$ indoor temperature is higher than the reference one, the air conditioner should be actuated (and vice-versa for the heating device). On the other hand, IF the difference between the indoor temperature and the reference one is lower than the threshold limit (hysteresis), THEN both heating and air conditioning devices are switched off.

d. Humidity: $I F$ the difference between the indoor humidity and the reference one is greater than or equal to the limit threshold, THEN the humidifier is activated. On the other hand, $I F$ the difference between the indoor humidity and the reference one is below the threshold limit (hysteresis), THEN the humidifier is switched off. Note that the threshold is specified according to the desired comfort of the individuals and the hysteresis is the interval in which no action should be taken to protect the actuators against successive "turn on/off" in short periods of time.

e. Air pollution: $I F$ the indoor air pollution index is greater than or equal to the limit threshold, THEN the extractor fan is activated and an audible alarm is issued. On the other hand, IF the indoor air pollution rate is lower than the threshold limit THEN both fan and alarm are switched off.

f. Automatic lighting algorithm: The proposed algorithm of automatic lighting can be presented by the following graph (Fig. 3) describing the general functioning of the system.

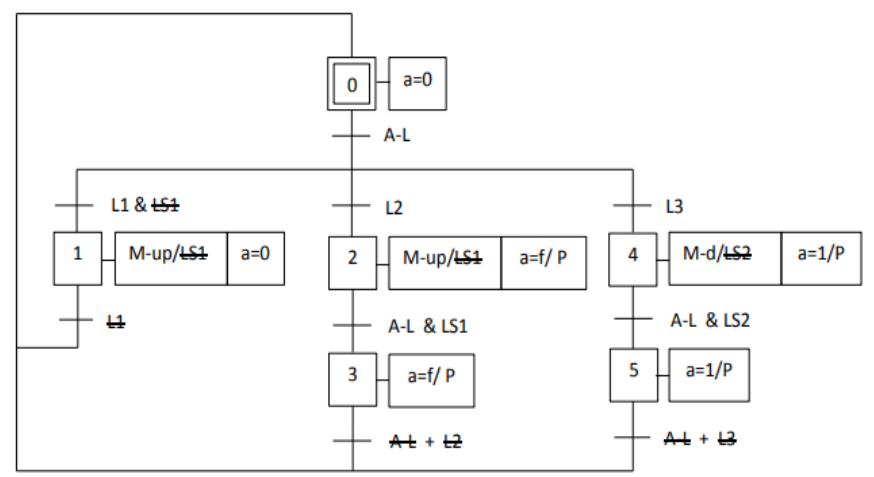

Fig. 3. House lighting Sequence Function Charts (SFC)

Where:

- $\quad$ LS1 (LS2) is the limit switch indicating that the shutters are up (down).

- M-up (M-d) represent the order given to the motor to turn in the direction of opening (closing) the windows shutters.

- A-L is the button allowing enabling/disabling the automatic lighting.

- $\quad \mathrm{P}$ indicates the presence of at least one person in the room.
- L1 indicates a high external luminosity rate.

- L2 indicates insufficient external luminosity rate.

- L3 indicates a very low external luminosity rate.

- " $a$ " is the duty cycle of the LED power signal.

\section{HARDWARE AND SOFTWARE DESIGN}

\section{A. Required Electronic Components}

According to the proposed home automatic control algorithm, the following modules are required to implement the automatic control system:

- $\quad$ PIC18F4550 to implement the lighting control

- PIC16F877A for the temperature control and the air pollution rate monitoring

- Stepper motor for motorization of the shutters and a DC motor powered via the L293D (quadruple high-current half $\mathrm{H}$ driver) is designed to provide bidirectional drive currents up to $600 \mathrm{~mA}$ at voltages from $4.5 \mathrm{~V}$ to $36 \mathrm{~V}$ ). L293D were used to have rotation in both directions.

- Light sensor LDR to measure the daylight. LDR's or Light Dependent Resistors are light dependent devices whose resistance is decreased when light falls on them and that is increased in the dark. [17].

- LED luminaires known for their low consumption are used for interior lighting.

- PIR "Passive Infrared" sensors to detect the presence of individuals. They are small, inexpensive, low-power and easy to use. This sensor is able to detect low Infra-Red radiation emission. As a motion detector, this one is actually split in two halves. The reason for that is we are looking to detect motion not average IR levels [17]. So to make automatic night lighting, LDR and PIR sensors must work together. The LDR will function as a light sensor while the PIR sensor will detect human bodies. During the day, the resistance of LDR is quite low which causes less voltage drop across it. In absence of bright light, the voltage drop across LDR is high as the resistance is high. PIR sensor uses the infrared radiations emitted from human body to detect a presence and produces an output voltage of $3.3 \mathrm{~V}$. When voltage level of both LDR and PIR sensors are high, PIC18F4550 microcontroller turns on the night light automatically. In this way, the automatic night light doesn't remain on throughout the whole night and saves significant amount of power. It only turns on automatically when we need it at night and remains switched off when there is no human around. The algorithm of lighting using LDR and PIR sensors is shown in Fig. 4.

- The MQ-2 sensor was used to monitor the rate of indoor air pollution. MQ-2 gas sensor has high sensibility to LPG, propane and hydrogen, also could be used to methane and other combustible steam. It is low cost and 
suitable for different applications. Sensitive material of MQ-2 gas sensor is $\mathrm{SnO}_{2}$. When the target combustible gas exist, the sensor's conductivity is higher along with the gas concentration rising.

- A buzzer is used to alert neighbor residents in the case of gas leak or fire (smoke). Furthermore, an extractor fan is used to evacuate the pollutant gas.

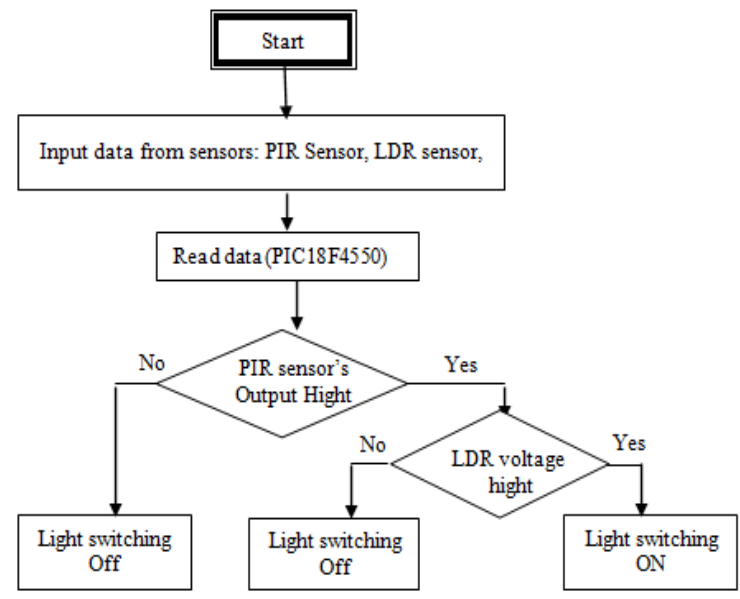

Fig. 4. Working principle of light control using LDR and PIR sensors.

- $\quad$ LM35 sensor is used to measure the indoor temperature. The operating temperature range is from $-55^{\circ} \mathrm{C}$ to $150{ }^{\circ} \mathrm{C}$. The output voltage varies by steps of $10 \mathrm{mV}$ in response to every 1 degree Celsius rise in temperature.

- DHT11 is a low cost digital temperature and humidity sensor. Its provides relative humidity value in percentage (20 to $90 \% \mathrm{RH}$ ) and temperature values in degree Celsius $\left(0\right.$ to $\left.50{ }^{\circ} \mathrm{C}\right)$.

\section{B. Software Design}

The algorithm for the proposed automation system was implemented in the PIC microcontrollers, while the testing of the entire circuit was carried out according to following steps:

\section{Program writing using Micro $C$ language}

2. Simulation using the Proteus software on which the control of both temperature and air pollution were implemented using PIC16F877A (Fig. 5), while the lighting control was executed with PIC18F4550 (Fig. 6).

3. Once the software simulations have been tested successfully, practical tests were carried on the EasyPIC V.8 Board [18] which allows loading the program on the microcontroller and performing various tests with the push buttons and LEDs used as inputs and outputs, respectively.

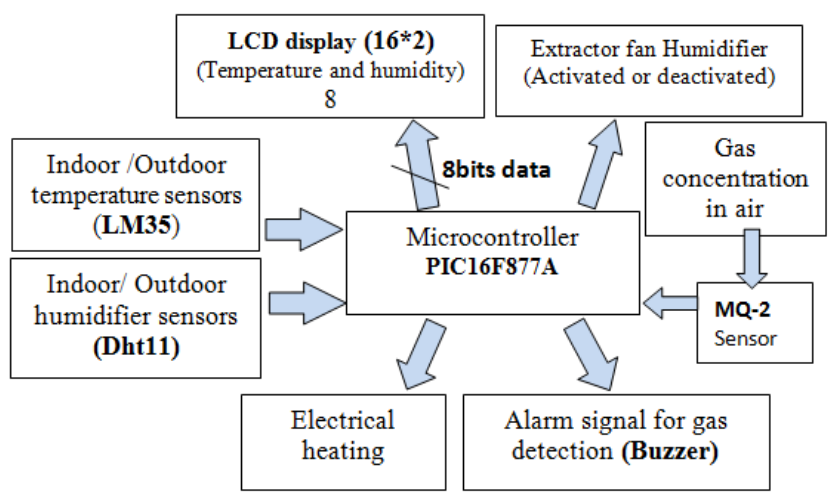

Fig.5. Temperature/air pollution control block diagram

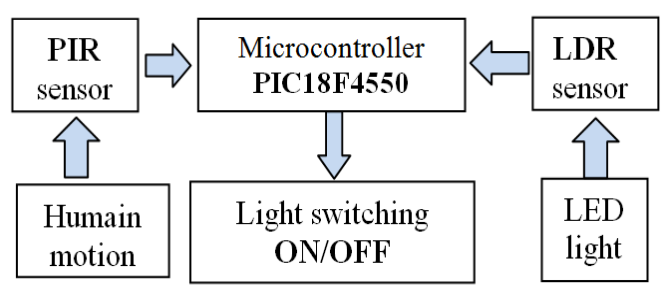

Fig. 6. Lighting control block diagram

\section{CONTROL CIRCUIT IMPLEMENTATION}

This control system consists of two programs running independently and the two programs were tested by Proteus software. The control circuit presented in Fig. 7 was made on a test board and has worked properly; it can subsequently be realized on printed circuit board.

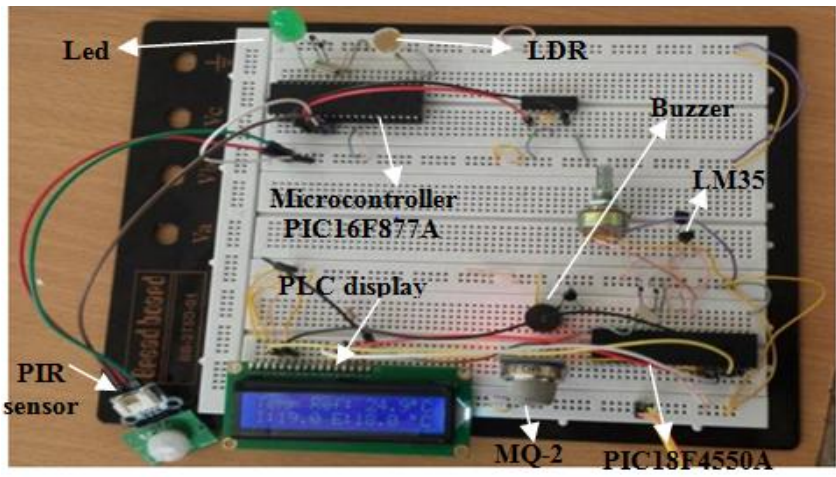

Fig.7. Electronic circuit of the proposed automatic control using PIC18F4550 and PIC16F877A

\section{COST ANALYSIS}

Hardware cost for the presented circuit is much cheaper than the existing "commercial" circuits. Total hardware cost for the system described in this study is listed in TABLE I. This cost is significantly lower compared to a common lighting control system that incorporates a light/motion/occupancy sensor (cost: €100-150) and to more sophisticated systems with imaging sensors and other high-end components (cost $>€ 1000$ ).

TABle I. COST OF AUtOMATION SyStem Without ACtUators [19].

\begin{tabular}{|c|c|c|c|}
\hline Product Name & Unit Price $(€)$ & Quantity & Sub-Total $(€)$ \\
\hline PIC18F4550 & 3.00 & 01 & 3.00 \\
\hline PIC16F877A & 2.79 & 01 & 2.79 \\
\hline
\end{tabular}




\begin{tabular}{|c|c|c|c|}
\hline $\begin{array}{c}\text { PIR sensor } \\
\text { HC-SR-501 }\end{array}$ & 0.50 & 01 & 0.50 \\
\hline LDR sensor & 0.10 & 01 & 0.10 \\
\hline LM35 sensor & 0.50 & 02 & 1.00 \\
\hline L293D & 0.50 & 01 & 0.50 \\
\hline MQ-2 sensor & 0.50 & 01 & 0.50 \\
\hline Buzzer & 0.50 & 01 & 0.50 \\
\hline DHT11 & 0.90 & 02 & 1.80 \\
\hline LCD display & 3.00 & 01 & 3.00 \\
\hline others & 4.00 & 01 & 4.00 \\
\hline \multicolumn{2}{|c|}{ Total cost: $17.69 €$} \\
\hline
\end{tabular}

The costs stated in TABLE I are unit costs for the individual components. In case of a production of such a system in high volumes, the cost is expected to drop significantly. On the other hand, the main functionality of the proposed system serves the main automation goals.

\section{VIII.CONCLUSION}

The design and implementation of a microcontroller-based automatic control system in smart house was achieved with low cost components that can be widely used in developing countries. The developed circuit will make the house more comfortable and safer for inhabitants and will consume less energy.

This design can be easily adapted to any house, which requires the use of sensors. The microcontroller-based house automatic control system designed in this study can be used in several cases such as: local authorities, public car parks, residential parking lots, hospitals, etc. To efficiently implement this kind of system, it is mandatory to understand the basics of the sensor characteristics, microcontroller operation and assembly language principles. Sensors serve as transducers for people detection while the programming language is fundamental to software design, based on the system requirements, specifications and planned operation of the system. Note that the limitation of this design depends on the sensors reliability. Using this design, it was possible to reduce the total cost of the control unit and the energy consumption of the infrastructure that is controlled by this system.

The following suggestions should be considered for further research work:

1. Better sensors should be considered that offer increased functionality. For instance, a suitable sensor, such as infrared ones, should be used in together with the LDR sensors which operates only with the presence of light. Infrared sensors are suitable in all situations as they do not depend on the light but the heat coming from the people entering the rooms

2. Use other microcontrollers like Arduino (or similar) that can manage all the actuators and sensors that are integrated in the house. The data sent by the sensors can be received and processed by the Arduino board which will then transmit them to an Ethernet component and thus allowing the visualization of them in the local network or on the Internet.
3. Implement the system and the sensors in a real house and study their behavior for a long term in order to test all the parameters and to assess the potential of energy savings.

\section{ACKNOWLEDGMENT}

This research is part of the PHC "Maghreb" (Programme Hubert Curien) MELINA (Mastering Efficient Lighting in North Africa) granted to L.C. and funded via Campus France by the French Ministry of Europe and Foreign Affairs and Algerian Ministry of Higher Education and Scientific Research. On the other hand, it was performed under "Projet Impact Socio-Économique", Contract N 185, funded by the General Directorate of Algerian Scientific Research.

\section{REFERENCES}

[1] https://www.iea.org/countries/algeria

[2] https://www.iea.org/policies/6103-renewable-energy-and-energyefficiency-development-plan-2015-2030

[3] Bouznit, M.; Pablo-Romero, M.P.; Sánchez-Braza, A. Residential Electricity Consumption and Economic Growth in Algeria. Energies $2018,11,1656$

[4] M. Missoum, A. Hamidat, L. Loukarfi, Energy Performance Simulations of a Grid-connected PV System Supplying a Residential House in the North-western of Algeria, Energy Procedia, Volume 50, Pages 202-213, 2014,

[5] Fathia Chekired, Achour Mahrane, Zoubeyr Samara, Madjid Chikh, Abderrazak Guenounou, Aissa Meflah, Fuzzy logic energy management for a photovoltaic solar home, Elsevier, Energy Procedia 134 (2017) 723-730.

[6] Tascikaraoglu A, Boynuegri A.R, Uzunoglu M. A demand side management strategy based on forecasting of residential renewable sources: A smart home system in Turkey. Energ Buildings 2014; 80:309-320.

[7] L.T. Doulos, A. Kontadakis, E.N. Madias, M. Sinou, A. Tsangrassoulis, Minimizing energy consumption for artificial lighting in a typical classroom of a Hellenic public school aiming for near Zero Energy Building using LED DC luminaires and daylight harvesting systems, Energy and Buildings, Volume 194, 2019, Pages 201-217, ISSN

0378-7788, https://doi.org/10.1016/j.enbuild.2019.04.033.

[8] Dubois, M. C., \& Blomsterberg, Å. (2011). Energy saving potential and strategies for electric lighting in future North European, low energy office buildings: A literature review. Energy and Buildings, 43(10), 2572-2582.

[9] L.T. Doulos, A. Tsangrassoulis, P.A. Kontaxis, A. Kontadakis, F.V. Topalis, Harvesting daylight with LED or T5 fluorescent lamps? The role of dimming, Energy and Buildings, Volume 140, 2017, Pages 336-347, ISSN 0378-7788, https://doi.org/10.1016/j.enbuild.2017.02.013.

[10] L. Doulos, A. Tsangrassoulis, F.V. Topalis, Multi-criteria decision analysis to select the optimum position and proper field of view of a photosensor, Energy Conversion and Management, Vol. 86, 2014, pp1069-1077, DOI : 10.1016/j.enconman.2014.06.032.

[11] Akanmu, A., Anumba, C., \& Messner, J. (2013). Active Monitoring and Control of Light Fixtures during Building Construction and Operation: Cyber-Physical Systems Approach. Journal of Architectural Engineering, 20(2), 04013008.

[12] Tan, Y. K., Huynh, T. P., \& Wang, Z. (2013). Smart personal sensor network control for energy saving in DC grid powered LED lighting system. Smart Grid, IEEE Transactions on, 4(2), 669-676.

[13] B. Mizon, (2012). Light pollution: responses and remedies. Springer Science \& Business Media.

[14] Adam, G.K.; Kontaxis, P.A.; Doulos, L.T.; Madias, E.-N.D.; Bouroussis, C. A.; Topalis, F. V. Embedded Microcontroller with a 
CCD Camera as a Digital Lighting Control System. Electronics 2019, $8,33$.

[15] C. A. Bouroussis, F. V. Topalis, "Smart multi-workplane lighting control and utilization of daylight using an imaging photosensor", 16 IEEE International Conference on Environment and Electrical Engineering, 7-10 June, 2016, Florence, Italy

[16] Fathia Chekired, Zoubeyr Smara, Achour Mahrane, Madjid Chikh, Smail Berkane, An energy flow management algorithm for a photovoltaic solar Home, Energy Procedia 111 (2017) 934 - 943
[17] Pyroelectric ("Passive") InfraRed Motion Sensor Datasheet : https://cdn-learn.adafruit.com/downloads/pdf/pir-passive-infraredproximity-motion-sensor.pdf

[18] https://www.mikroe.com/easypic

[19] Online components reseller from Alibaba_Group ; Website : https://french.alibaba.com/ (accessed March 2020) 